\title{
Fitness Wearables: Indispensable Assistant or Useless Gadget?
}

\author{
Michel Plaisent, Sylvain Favreau, Prosper Bernard
}

\begin{abstract}
Nowadays the IoT importance is growing not only economically but also in our daily life. Among these objects wearables, namely the fitness trackers are introduced with great success, mostly but not only in developed countries. But little is known about the attitudes of physical education students about their most important features and how useful they are perceived. This communication presents he results of an exploratory study aimed at a better understanding of the situation with an initial portrait.
\end{abstract}

Keywords - IoT, wearables, smartwatch, fitness trackers.

\section{INTRODUCTION}

Bandyopadhyay \& Sen (2011) view the IoT at the convergence of the things-oriented (objects, sensors, transmitters, etc.), internet-oriented (IP connectivity, web, etc.) and semantic-oriented (smart middleware, reasoning technologies, tc.) visions. Miorandi et al. (2012) define smart objects as characterized by the following:

- Have a physical embodiment;

- Have a minimal set of communication functionalities;

- Possess a unique identifier;

- Are associated to at least one name and one address to communicate;

- Possess some basic computing capabilities.

- May possess means to sense physical phenomena (e.g., temperature, light, etc.)

$<$

An approach to classification suggests to consider ther maturity in a model of Etwaru (2016), from dumb to smart objects. The level of smartness is defined by Jain (2014) as follow:

1. Passive: Communicate only when queried. Passive RFID, $Q R$ codes

2. Active: Communicate when needed. Sensors. Home automation (1-4 sense)

3. Aware: Action based on simple computation. E.g., telehealth (5-sense)

4. Autonomous: Can make decisions based on rules. E.g., autonomous cars, smart grid (Human)

Among the many equivalent classifications of application domains available, Texas Instrument (2016) distinguishes between building \& home automation, smart cities, smart manufacturing, automotive, health care and wearables. Alrige \& Chatterjee (2015) suggest a classification based on application, form and functionality. A more detailed grouping is suggested by Dlodlo et al. (2012) as following: medical technology/health, retail/logistics and supply chain management ; transport; insurance; energy; information security, home automation; environment monitoring; manufacturing; agriculture; education; telecommunication. Health is often grouped with fitness while fitness is under wearables.

Wearable technologies with body sensors would also be of great value when appropriately used in a classroom , assisting students with disabilities and collecting data from these devices to assess a global portrait of the classroom (Borthwick, 2015).

The global wearable technology market is forecasted to grow from 0.75 billion in 2012 to 5.8 billion in 2018 (Statista, 2016). The global smart wearable fitness market is expected to grow at a compound annual rate of over $25 \%$ by 2020 (Technavio, 2016). Almost 20 million of fitness trackers were shipped in first Quarter of 2016 (an increase of 67\% over same quarter of last year) according to IDC (2016). Chamberlin (2014) from IBM predicted for 2015 that smartwatches and fitness trackers would be among the main wearable trends to watch in. Jesdanun (2015) suggest that despite the actual growing sales, the enthusiasm for fitness trackers can fade with time as it has already been observed by Endeavour Partners, "who estimates that about a third of these trackers get abandoned after six months".

Despite this growing popularity, too few studies have been conducted to better understand user perceptions and attitudes (Kim \& Shin, 2015). More specifically, market research are usually targeted toward consumers in general while people actually performing physical education are not distinguished, namely students despite they may be good representatives of innovation introduction in the courses potentially needing one of these devices. The purpose of this communication is then to partially fill this hole by drawing a portrait of fitness devices most attracting characteristics and most important perceptions toward their use by this subpopulation.

\section{BACKGROUND}

The main features of these devices do not have the same importance for everyone, as the need may vary with the complexity or intensity of the fitness tasks, the athletes' needs being much more sophisticated than those of the jogger. Nowadays these devices are not only technological object but also fashion ware, so their design and appeal, and social 
marker, maybe important in relation to the intention to use them.

Among the other variables potentially related to intention to use such devices, the perceived usefulness and perceived ease of use are candidates often associated with technology acceptance and decision to use.

Clearly more knowledge is needed on fitness trackers and this work in progress paper aims to fill partially this hole. We propose the diagram below for our framework. This exploratory study will draw a portrait of the perception of physical education students as a preliminary step to a better understanding

\section{Methodology}

In order to get data rapidly, and given the fact that the topic is already well documented, a questionnaire was preferred to interviews. The questionnaire comprises 2 sections: attitude toward the devices, measure by 5 points Liker scales, ranging from $1=$ totally disagree to $5=$ totally agree. Perceived usefulness of main functions; socio-demographic. The first section is made of 12 questions taken from the instrument of Kim \& Shin, 2015). Most of the constructs are measured by only one item. The second section contains 17 features of tracking devices, that the respondent must assess in terms of importance for their use, in a five-point scale, varying from $1=$ not at all important to 5 of the greatest importance. Finally the questionnaire asks for gender and how important is the cost in their potential decision to buy a device.

The questionnaire was administrated to junior high school student of a private and most important university of Philippines. Among the 186 questionnaires received, we count 110 females $(63.1 \%)$ versus 66 males $(36.9 \%)$.

\section{RESULTS}

The data analysis was performed with SPSS version 20. The main results are presented below, in Table 1 ..

As it appears from Table 1, the most popular functions are the continuous monitoring of heart rate (mean=3.84), the impermeability to water $($ mean $=3.67)$ and the clock (mean=3.57). The least useful functions seem to be the measurement of flook climbed (mean=2.70), with the barometer (mean=2.78) and the auto-sleep detector $($ mean=2.81). No function appear to be a winner, able to give enthusiasm.

TABLE I APPRECiATION OF THE FEATURES

\begin{tabular}{|c|c|c|c|c|c|c|}
\hline features & Valid & Missing & Mean & Median & Mode & $\begin{array}{c}\text { Std. } \\
\text { Deviation }\end{array}$ \\
\hline continuous heart rate & 184 & 1 & 3.84 & 4 & 3 & 0.959 \\
\hline swim proof & 184 & 1 & 3.67 & 4 & 5 & 1.122 \\
\hline clock & 185 & 0 & 3.57 & 3 & 3 & 1.004 \\
\hline multi-sport & 185 & 0 & 3.39 & 3 & 3 & 0.921 \\
\hline music control & 185 & 0 & 3.38 & 3 & 3 & 1.117 \\
\hline steps, calories, distance & 185 & 0 & 3.36 & 3 & 3 & 0.923 \\
\hline active minutes & 185 & 0 & 3.28 & 3 & 3 & 0.935 \\
\hline text notification & 185 & 0 & 3.21 & 3 & 3 & 1.075 \\
\hline reminders to move & 185 & 0 & 3.18 & 3 & 3 & 0.97 \\
\hline caller ID & 184 & 1 & 3.17 & 3 & 3 & 1.062 \\
\hline sleep tracking & 184 & 1 & 3.11 & 3 & 3 & 1.002 \\
\hline connected GPS & 185 & 0 & 3.11 & 3 & 3 & 1.193 \\
\hline auto exercise recognition & 185 & 0 & 3.06 & 3 & 3 & 0.959 \\
\hline auto sleep detection & 184 & 1 & 2.81 & 3 & 3 & 1.072 \\
\hline barometer & 184 & 1 & 2.78 & 3 & 3 & 0.855 \\
\hline floors climbed & 183 & 2 & 2.70 & 3 & 3 & 0.955 \\
\hline
\end{tabular}


The Table 2 presents the perceptions of the respondents in regard of their intention to buy or use such a device

TABLE II

PERCEPTIONS OF RESPONDENTS IN REGARD OF ATTITUDE

\begin{tabular}{|l|c|c|c|c|c|}
\hline perceptions & Valid & Mean & Median & $\begin{array}{c}\text { Std. } \\
\text { Mede }\end{array}$ \\
\hline such a fitness device is expensive & 185 & 3.69 & 4.00 & 3 & .938 \\
\hline Overall, using such a fitness device seems beneficial & 185 & 3.64 & 4.00 & 4 & .802 \\
\hline $\begin{array}{l}\text { these devices would be helpful in my personal life (even } \\
\text { if not in my work) }\end{array}$ & 184 & 3.59 & 3.00 & 3 & .943 \\
\hline I plan to use such a fitness device & 182 & 3.55 & 4.00 & 3 & .870 \\
\hline I thing that such a fitness device is easy to use & 183 & 3.55 & 4.00 & 3 & .856 \\
\hline $\begin{array}{l}\text { such a fitness device would be useful in doing my job } \\
\text { I have a generally favorable attitude toward using such a } \\
\text { fitness device }\end{array}$ & 184 & 3.54 & 3.50 & 3 & .916 \\
\hline such a fitness device is attractive and pleasing & 185 & 3.40 & 3.00 & 3 & .709 \\
\hline $\begin{array}{l}\text { such a fitness device offers tha sense of real-time } \\
\text { connectedness }\end{array}$ & 185 & 3.39 & 3.00 & 3 & .814 \\
\hline I think that I can use such a fitness device anywhere & 184 & 3.26 & 3.00 & 3 & .983 \\
\hline these devices cost too much for their usefulness & 184 & 3.22 & 3.00 & 3 & .847 \\
\hline $\begin{array}{l}\text { such a fitness device helps people who use it stand apart } \\
\text { from the crowd }\end{array}$ & 185 & 3.11 & 3.00 & 3 & .938 \\
\hline I would be able to easily afford such a fitness device & 185 & 2.59 & 3.00 & 3 & .934 \\
\hline $\begin{array}{l}\text { people who use such a fitness device would be considered } \\
\text { leasders rather than followers }\end{array}$ & 185 & 2.49 & 2.00 & 3 & .984 \\
\hline
\end{tabular}

The general attitude of respondents is relatively positive with a mean of 3.64 , despite these devices are judged as expensive (3.69). These devices are perceived as useful and the respondents plan to acquire or use one of these. The social impact of using these device as a social differentiators does not get many support (mean=2.49).

Table 3 differentiates between respondents in terms of ownership of such devices. One out of four already own such a device and intend to continue to use it, while more than one third do not intend to buy one of these

TABLE III

OWNERSHIP ACTUAL AND PLANNED

\begin{tabular}{|c|c|c|}
\hline Frequency & Percent & $\begin{array}{l}\text { Valid } \\
\text { Percent }\end{array}$ \\
\hline $\begin{array}{l}\text { i do not own } \& \text { dont intend to } \\
\text { buy }\end{array}$ & 69 & 37.3 \\
\hline I intend to buy ASAP & 63 & 34.1 \\
\hline $\begin{array}{l}\text { I own and intend to continue to } \\
\text { use }\end{array}$ & 46 & 24.9 \\
\hline
\end{tabular}

In order to determine the impact of this variable, an ANOVA test was computer with the Scheffe coefficients. As it appears in Table 4, owning a device generate a positive attitude (mean $=3.59$ ); the device does not appear beneficial enough to convince those who don't own and don't intend to own (4.49) The price seems to be the main factor as those who disagree with the affordability statement (mean=2.25) don't intend to buy.

\section{V.CONCLUSION}

The market of smartwatches and tracking devices may be growing but these devices are still expensive and their use still not totally integrated in life style according to our respondents. But our sample choice may explain some of these findings, namely in consideration of age of respondents and their economic relative incapacity. Clearly more research is needed. 
TABLE 4: ANOVA TEST FOR OWNERSHIP OF DEVICE

\begin{tabular}{|c|c|c|c|c|}
\hline perceptions / subsets (set 1 in bold) & $\begin{array}{l}\text { i do not own \& dont } \\
\text { intend to buy }\end{array}$ & I intend to buy ASAP & $\begin{array}{l}\text { lown and intend to } \\
\text { continue to use }\end{array}$ & nbr groups \\
\hline I have a generally favorable attitude toward using such a fitness device & 3.13 & 3.59 & 3.59 & 2 \\
\hline Overall, using such a fitness device seems beneficial & 4.49 & 3.48 & 3.72 & 1 \\
\hline I plan to use such a fitness device & 3.15 & 3.82 & 3.76 & 2 \\
\hline I thing that such a fitness device is easy to use & 3.47 & 3.66 & 3.52 & 1 \\
\hline such a fitness device would be useful in doing my job & 3.49 & 3.65 & 3.54 & 1 \\
\hline such a fitness device is attractive and pleasing & 3.09 & 3.57 & 3.59 & 2 \\
\hline I think that I can use such a fitness device anywhere & 3.00 & 3.57 & $3.24 / 3.24$ & 2 \\
\hline such a fitness device offers tha sense of real-time connectedness & 3.28 & 3.41 & 3.35 & 1 \\
\hline such a fitness device helps people who use it stand apart from the crowd & 2.94 & 3.17 & 3.11 & 1 \\
\hline $\begin{array}{l}\text { people who use such a fitness device would be considered leaders rather } \\
\text { than followers }\end{array}$ & 2.14 & $2.57 / 2.57$ & 2.8 & 2 \\
\hline such a fitness device is expensive & 3.33 & 3.76 & 3.9 & 2 \\
\hline I would be able to easily afford such a fitness device & 2.25 & 2.75 & 2.80 & 2 \\
\hline these devices cost too much for their usefulness & 3.22 & 3.19 & 3.24 & 1 \\
\hline these devices would be helpful in my personal life (even if not in my work) & 3.14 & 3.87 & 3.89 & 2. \\
\hline
\end{tabular}

\section{REFERENCES}

[1] Bandyopadhyay, Debasis \& Sen,Jaydip (2011). Internet of Things: Applications and Challenges in Technology and Standardization. Wireless Personal Communications, May 2011, Volume 58, Issue 1, pp 49-69

https://doi.org/10.1007/s11277-011-0288-5

[2] Borthwick, Arlene C., Cindy L. Anderson, Elizabeth S. Finsness \& Teresa S. Foulger (2015). Special Article Personal Wearable Technologies in Education: Value or Villain?, Journal of Digital Learning in Teacher Education, 31:3, 85-92, DOI:10.1080/21532974.2015.1021982ISSN: 2153-2974 (Print) 23327383 (Online) Journal homepage: http://www.tandfonline.com/loi/ujdl20

[3] Chamberlin, Bill (2014). Wearable Computing A 2014 Horizon Watching Trend Report, IBM, April 7, 2014

[4] Dlodlo, Nomusa; Foko, Thato; Mvelase, Promise; Mathaba, Sizakele (2012). The State of Affairs in Internet of Things Research. Electronic Journal of Information Systems Evaluation 15.3 (Nov 2012): 244258.

[5] Etwaru, Richie (2016). IMS health (2016). Inside IoT \& Wearables. Slideshare.

[6] Health 2.0 - Internet of Things (IoT) and Wearables. https://www.imshealth.com/files/web/Corporate/News/In\%20the\%20N ews/IMS\%20Health\%20London\%20CIO\%20Roundtable\%20\%20PME\%20-\%20May\%202016.pdf

[7] IDC (2016). Worldwide Wearables Market Increases 67.2\% Amid Seasonal Retrenchment. IDC Worldwide Quarterly Wearables Tracker, May 16, 2016

http://www.idc.com/getdoc.jsp?containerId=prUS41284516

[8] IDC (2015). The Next Big Thing on Devices in the Philippines: IDC's Market Outlook for Smart Devices. 13 Jul 2015. ttps://www.idc.com/getdoc.jsp?containerId=prPH25750315

[9] Jain, Raj (2014). Levels of Smartness. http://go.gigaom.com/rs/gigaom/images/gigaomresearch_the_internet_ of_things_report.pdf

[10] Jesdanun, Anick (2015). Have we had enough of fitness trackers? ABS-CBN Jul 09, 2015 12:19 PM.

http://lifestyle.abs-cbn.com/articles/0273/have-we-had-enough-offitness-tracker

[11] Kim, Joon Ki and Shin, Dong-Hee (2015). An acceptance model for smart watches: implications for the adoption of future wearable technology. Internet Research, Vol 25, no 4, 527-541. Emerald Group Publishing Limited 1066-2243 DOI 10.1108/IntR-05-2014-0126 https://doi.org/10.1108/IntR-05-2014-0126

[12] ttps://doi.org/10.1016/j.adhoc.2012.02.016 ttps://doi.org/10.1016/j.adhoc.2012.02.016
[13] Statista (2016). Forcasted value of the global wearable devices from 2012 to 2018 (in billion US \$). https://www.statista.com/statistics/302482/wearable-device-marketvalue/

[14] Technavio (2016). Global Smart Wearable Fitness and Sports Devices and Services Market 2016-2020. http://www.technavio.com/report/global-machine-machine-m2m-andconnected-devices-smart-wearable-fitness-and-sports-devices

[15] Texas Instrument (2016). Application Areas for the Internet of Things. http://www.ti.com/ww/en/internet_of_things/iot-applications.html 